\title{
A case of esophageal tuberculosis diagnosed by polymerase chain reaction
}

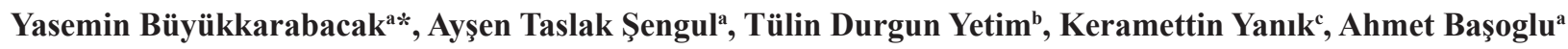 \\ ${ }^{a}$ Department of Thoracic Surgery, Ondokuz Mayls University, Samsun, Turkey \\ ${ }^{b}$ Department of Thoracic Surgery, Mustafa Kemal University, Hatay, Turkey \\ ${ }^{c}$ Department of Clinical Microbiology, Ondokuz Mayls University, Samsun, Turkey
}

\section{ARTICLE INFO ABSTRACT}

\section{Article History}

$\begin{array}{ll}\text { Received } & 25 / 09 / 2012 \\ \text { Accepted } & 09 / 10 / 2012\end{array}$

\section{* Correspondence to:}

Yasemin Buyukkarabacak

Department of Thoracic Surgery,

Medical School,

Ondokuz Mayıs University,

Atakum, Samsun, Turkey

e-mail: yaseminbuyukkarabacak@gmail.com
A 72-year-old female patient was admitted to the university hospital for dysphagia, retrosternal pain and weight loss. M.Tuberculosis DNA was identified in the fresh biopsy specimens by polimerase chain reaction (PCR) in a short time. She was diagnosed with esophageal tuberculosis and antituberculous treatment regimen was started. The symptoms diminished in two months. We would like to present an esophageal tuberculosis case diagnosed by PCR in fresh biopsy specimens.

J. Exp. Clin. Med., 2013; 30:85-87

\section{Keywords:}

Esophagus

Fast diagnosis

Fresh biopsy specimen

Tuberculosis

Polymerase chain reaction

\section{Introduction}

The major causes of solitary esophageal ulcers are Crohn's disease, pill-induced ulcers, Barret's Esophagus and infections of mycobacteria and viral or fungal infections (Rovekamp et al., 2005). Diagnosis of infectious ulcer is especially difficult. Esophageal tuberculosis was first described as a postmortem diagnosis by Denonvilliers in 1837 (Devarbhavi et al., 2003). It is rare even in the presence of extensive and severe pulmonary tuberculosis. $1 \mathrm{t}$ is usually secondary to tuberculous infection of other organs so results from direct extension of adjacent tuberculous foci such as mediastinal lymphadenopathy or primarily attributable to ingestion of infected sputum or occurred via direct extension from the adjacent mediastinal lymph node or hematogenous spread from the small endobronchial lesion remains unclear (Welzel et al., 2010). Polimerase chain reaction (PCR) has good sensitivity and specificity in the diagnosis of many infectious diseases and has been incorporated into clinical practice for some of them (Borges et al., 2009). In recent years, PCR has been frequently used for rapid diagnosis of mycobacterial infection. The sensitivity of PCR has been reported to be similar to that of culture (Fujiwara et al., 2003).

\section{Case}

A 72-year-old female patient was admitted to the university hospital due to dysphagia, retrosternal pain and weight loss, which had continued for two months. She had been using alendronat monosodium dihydrate and calcitonin for osteoporosis treatment for six years. There were no distinctive features in her family history. There was no pathological finding at the physical examination. Lymphadenopathy was not observed. The white blood cell (WBC) count was $9800 / \mathrm{mm}^{3}$, hemoglobine was $12 \mathrm{~g} / \mathrm{dl}$, and erythrocyte sedimentation rate was 44 $\mathrm{mm} / \mathrm{h}$. The human immunodeficiency virus (HIV) antibody test was negative. Serum chemistry was normal.

Chest X-ray was normal. In barium contrast study, mucosal irregularity was detected at the upper $1 / 3$ esophagus (Fig. 1). Computed tomography (CT) of the chest revealed that esophagus was wider than normal. Neither mediastinal nodular mass nor pulmonary lesion was detected at CT 


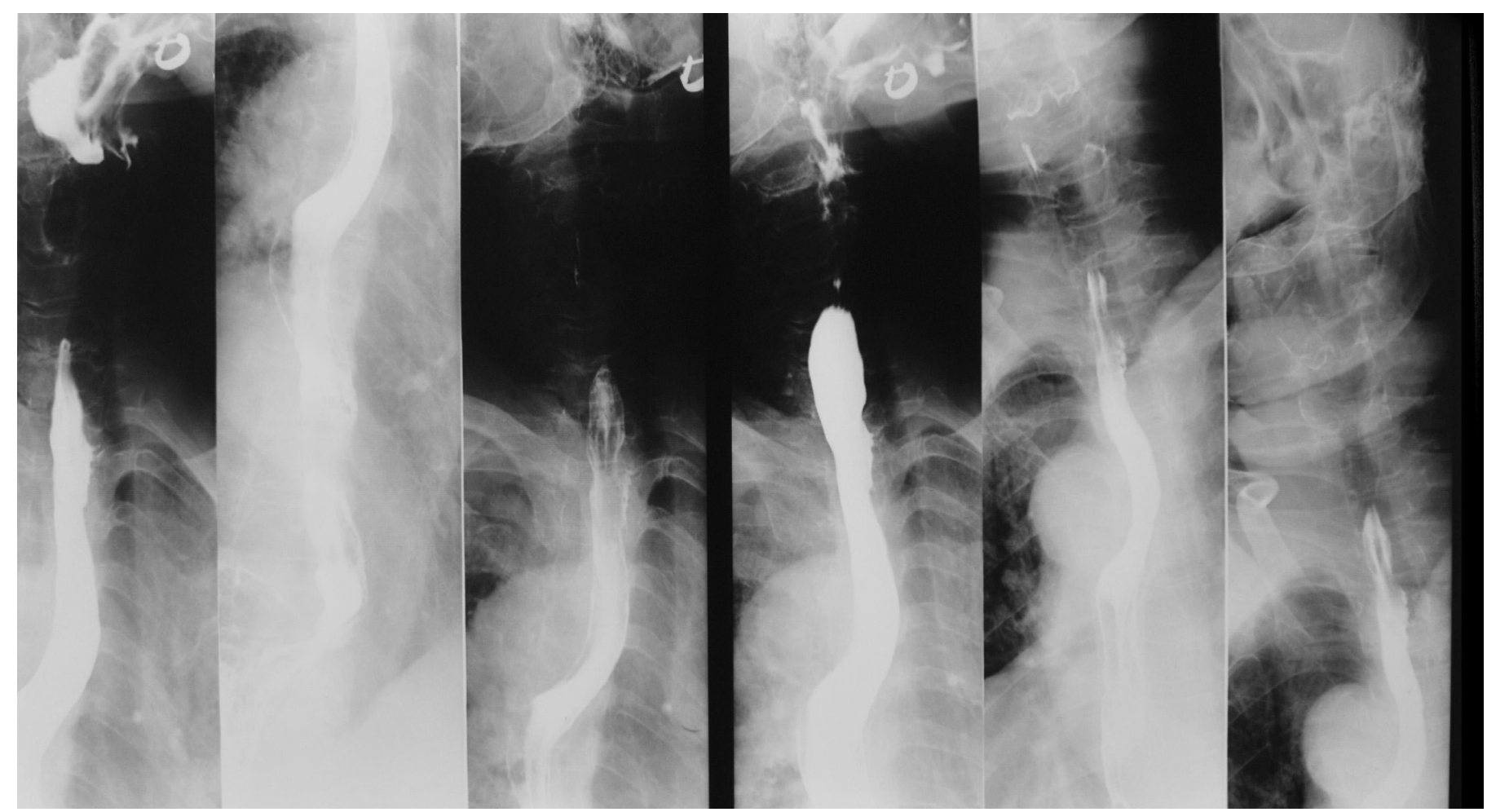

Fig. 1. Barium contrast study: Mucosal irregularity detected at the upper third esophagus.

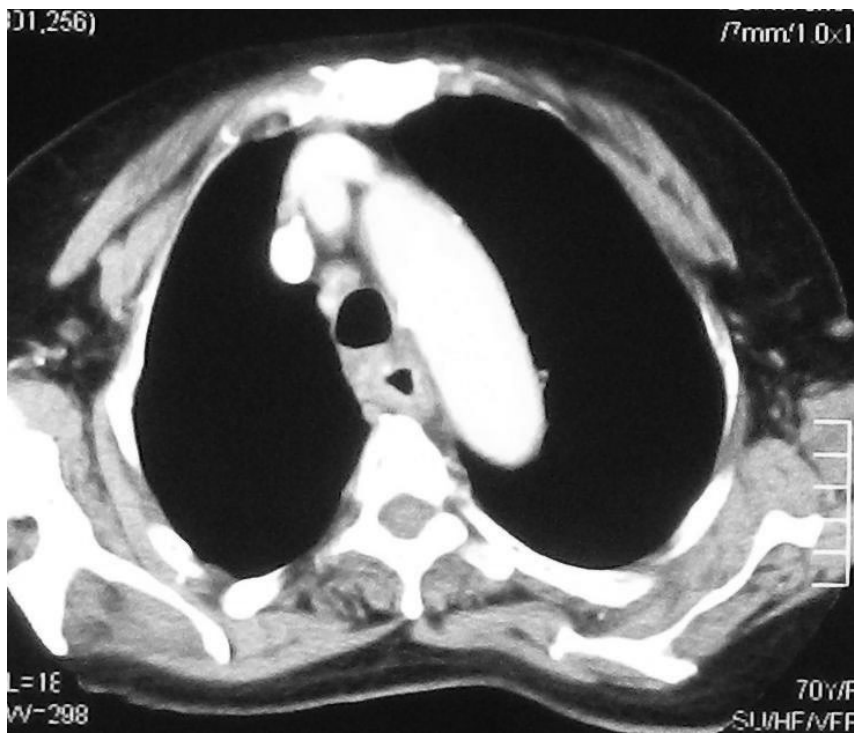

Fig. 2. Computed tomography of the chest: Esophagus was wider and esophagus wall was thicker than normal.

(Fig.2). In endoscopy, esophageal mucosa was irregular and pale in every $15-20 \mathrm{~cm}$ starting from the incisive teeth (Fig. 3). Multiple biopsies were taken from this area. Caseating granulomas and Langhans type giant cells were determined in histopathological examination.

Fresh biopsy specimens were stained with Ziehl-Neelsen and acid-fast bacilli were detected at the microscopic examination (Fig. 4). M.Tuberculosis DNA was determined in biopsy specimen by PCR in a short time. Since patient don't cough, sputum analysis could not be performed. The patient was treated with anti-tuberculosis treatment comprising isoniazid (INH), ethambutol, pyrazinamide and rifampicin. The patient responded well to the treatment in 2 weeks. She did not come to check but we learned that she had stopped the treatment herself and didn't accept endoscopic control. About one year after the last control, she was admitted to emergency department due to unconsciousness, loss of balance, diplopia and night fever. In cerebrospinal fluid (CSF) examination, WBC count was $270 / \mathrm{mm}^{3}$ ( $85 \%$ lymphocyte). CSF protein and glucose were determined as $174 \mathrm{mg} / \mathrm{dl}$ and $11 \mathrm{mg} / \mathrm{dl}$, respectively. Anti-tuberculosis treatment comprising INH, ethambutol, pyrazinamide, rifampicin was started empirically. CSF material was stained with Ziehl-Neelsen and acid alcohol resistant bacillus (AARB) was detected microscopically and M.Tuberculosis DNA was defined by PCR. M.Tuberculosis was grown in the CSF culture. Thorax CT was normal. Mediastinal lymphadenopathy could not be determined. The patient responded to the treatment well. Pyrazinamide and ethambutol were stopped at the end of the $2^{\text {nd }}$ month and the patient was discharged. Since then, we could not get any information about the patient.
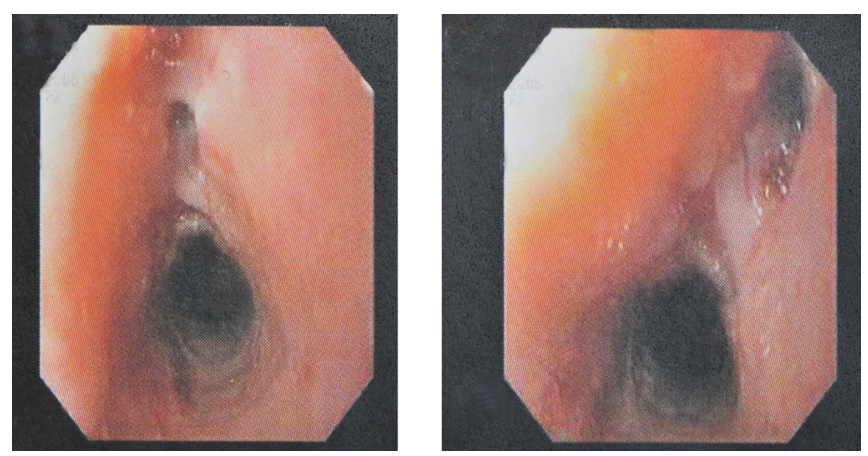

Fig. 3. Endoscopy: Esophageal mucosa was irregular and pale in every $15-20 \mathrm{~cm}$ starting from the incisive teeth.

\section{Conclusion}

Esophageal tuberculosis is observed especially in endemic areas and in immunosuppressed individuals (Welzel et al., 


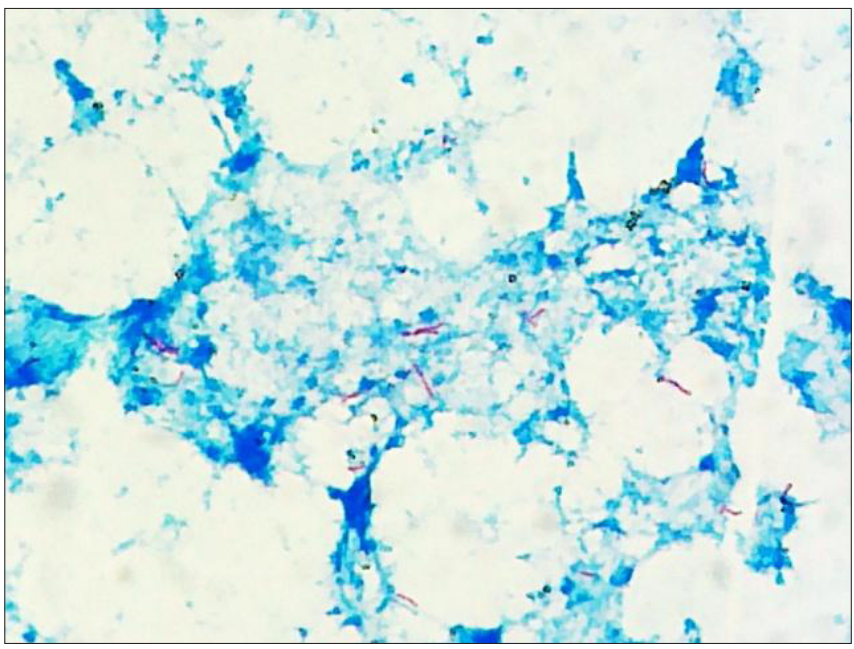

Fig. 4. The aside alkole rezistan basil detected at the microscopic examination.

2010). Esophageal involvement of tuberculosis was first identified by Denonvilliers in 1837 . However, primary tuberculosis of the esophagus was first reported by Torek in 1931 (J1bah and Sabaratnam, 1991). It has been reported to only account for approximately $0.2-1 \%$ of the reported gastrointestinal tuberculosis cases (Welzel et al., 2010; Lozano et al., 2011). Our patient did not have any of the risk factors. There was no medical history for tuberculosis. HIV antibody test was negative.

Primary esophageal tuberculosis is extremely rare. The most common symptoms of esophageal tuberculosis are dysphagia, weight loss, and retrosternal pain. Esophagogram can reveal the ulcers in the middle esophagus and the localized segmental stenoses. Deep and large ulcers and tract of fistula can be observed in the esophageal mucosa, and the esophageal wall is usually thickened. None of these symptoms or findings are pathognomonic to esophagus tuberculosis (Tüney, 2002).

The differential diagnosis of the esophageal tuberculosis can be made by identifying caseating tuberculous granulomas in endoscopic biopsy material and by growing M.tuberculosis in cultures (Fujiwara et al., 2003). We identified caseating tuberculous granulomas histologically, and acid-fast bacili were displayed in fresh endoscopic biopsy materials by Ziehl-Neelsen stain.

Methods to diagnose tuberculosis have been improved in recent years, and several molecular techniques have been introduced for clinical use. In recent years, PCR has been frequently used for rapid diagnosis of mycobacterial infection. It is very valuable for clinical use because differential diagnosis of tuberculosis can be confirmed within days by PCR. It provides several advantages over culture, including confirmation of the presence of $M$. tuberculosis within 1 to 3 days compared to 2 to 6 weeks with culture techniques. Rapid diagnosis of tuberculosis with sensitivity similar to that of culture has been reported in fresh specimens such as sputum and fluid aspirates by using PCR (Fujiwara et al., 2003). In our case, we suggested tuberculosis because granulomas were determined at the histological examination. While the fresh biopsy materials were stained with Ziehl-Neelsen, acid-fast bacilli were shown microscopically, and the DNA of Mycobacterium was identified with PCR. Consequently, we started antituberculous treatment in a short time. All of the symptoms diminished in two months. However, the patient did not keep to the antituberculous treatment and one year later, she was hospitalized due to tuberculosis meningitis.

Tuberculosis is an endemic pathology and a very important health problem in our country. Although, esophageal tuberculosis is a very rare condition even in the presence of extensive and severe pulmonary tuberculosis, it must be considered as diferential diagnosis in disphagia of unknown origin. The clinical diagnosis of esophageal tuberculosis requires a high index of suspicion because of its rarity and is based on a combination of clinical, radiological, endoscopic and histologic features and on response to therapy. When $M$. tuberculosis DNA is found in tissue specimens by PCR, this information must be taken together with histopathological data before diagnosis of tuberculosis was made. PCR is sensitive, specific, and rapid methods for the detection of mycobacteria in fresh biopsy material and it provides to make the diagnosis of tuberculosis in very short time.

\section{REFERENCES}

Borges, M.C., Colares, J.K.B., Lima, D.M., Fonseca, B.A.L., 2009. Advantages and pitfalls of the polymerase chain reaction in the diagnosis of esophageal ulcers in AIDS patients. Digest. Dic. Sci. 54, 1933-1939.

Devarbhavi, H., Alvares, J.F., Radhikadevi, M., 2003. Esophageal tuberculosis associated with esophagotracheal or esophagomediastinal fistula: Report of 10 cases. Gastrointest. Endosc. 57, 588-592.

Fujiwara, T., Yoshida, Y., Yamada, S., Kawamata, H., Fujimori, T., Imawari, M., 2003. A case of primary esophageal tuberculosis diagnosed by identification of Mycobacteria in paraffin-embedded esophageal biopsy specimens by polymerase chain reaction. J. Gastroenterol. 38, 74-78.

J1bah, E., Sabaratnam, S., 1991. Tuberculosis of the esophagus. Digest. Dis. Sci. 36, 536-540.

Lozano, A.S., Leibovich, N., Souto, G., Sabatini, C., Brodersen, C., Segal, E., 2011. Esophageal tuberculosis: Case report and review of the literature. Acta. Gastroenterol. Latinoam. 41, 47-51.

Rovekamp, B.T., Linde, K., Dees, J., Overbeek, S.E., Blankenstein, M.A., Kuipers, E.J., 2005. A solitary tuberculous ulcer in the oesophagus. Eur. J. Gastroen. Hepat. 17, 435-439.

Tüney, D., 2002. Özofagus hastalıklarının tıbbi ve cerrahi tedavisi: Özofagus radyolojisi, Yüksel, M., Başoğlu, A. eds. Bilmedya grup, İstanbul, pp. 21-43.

Welzel, T., Kawan, T., Bohle, W., Richter, G.M., Bosse, A., Zoller, W.G., 2010. An unusual cause of dysphagia: Esophageal tuberculosis. J. Gastrointest. Liver. 19, 321-324. 